\title{
Intraoperative fluorescence imaging to localize tumors and sentinel lymph nodes in rectal cancer
}

\author{
Henricus J.M. Handgraaf, Leonora S.F. Boogerd, Floris P.R. Verbeek, Quirijn \\ R.J.G. Tummers, James C.H. Hardwick, Coen I.M. Baeten, John V. Frangioni, \\ Cornelis J.H. van de Velde \& Alexander L. Vahrmeijer
}

To cite this article: Henricus J.M. Handgraaf, Leonora S.F. Boogerd, Floris P.R. Verbeek, Quirijn R.J.G. Tummers, James C.H. Hardwick, Coen I.M. Baeten, John V. Frangioni, Cornelis J.H. van de Velde \& Alexander L. Vahrmeijer (2016) Intraoperative fluorescence imaging to localize tumors and sentinel lymph nodes in rectal cancer, Minimally Invasive Therapy \& Allied Technologies, 25:1, 48-53, DOI: $10.3109 / 13645706.2015 .1042389$

To link to this article: http://dx.doi.org/10.3109/13645706.2015.1042389

Published online: 07 May 2015.

Submit your article to this journal ¿

Џ Article views: 76

View related articles \ulcorner

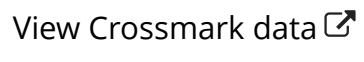




\title{
Intraoperative fluorescence imaging to localize tumors and sentinel lymph nodes in rectal cancer
}

\author{
HENRICUS J.M. HANDGRAAF ${ }^{1}$, LEONORA S.F. BOOGERD ${ }^{1}$, FLORIS P.R. VERBEEK ${ }^{1}$, \\ QUIRIJN R.J.G. TUMMERS ${ }^{1}$, JAMES C.H. HARDWICK ${ }^{2}$, COEN I.M. BAETEN ${ }^{1}$, \\ JOHN V. FRANGIONI ${ }^{3,4,5}$, CORNELIS J.H. VAN DE VELDE ${ }^{1}$, \\ ALEXANDER L. VAHRMEIJER ${ }^{1}$
}

${ }^{1}$ Department of Surgery, Leiden, The Netherlands, ${ }^{2}$ Department of Gastroenterology, Leiden, The Netherlands, ${ }^{3}$ Department of Radiology, Beth Israel Deaconess Medical Center, Boston, MA, USA, ${ }^{4}$ Division of Hematology/Oncology, Department of Medicine, Beth Israel Deaconess Medical Center, Boston, MA, USA, and ${ }^{5}$ Curadel, LLC, Worcester, MA, USA

\begin{abstract}
Tumor involvement at the resection margin remains the most important predictor for local recurrence in patients with rectal cancer. A careful description of tumor localization is therefore essential. Currently, endoscopic tattooing with ink is customary, but visibility during laparoscopic resections is limited. Near-infrared (NIR) fluorescence imaging using indocyanine green (ICG) could be an improvement. In addition to localize tumors, ICG can also be used to identify sentinel lymph nodes (SLNs). The feasibility of this new technique was explored in five patients undergoing laparoscopic low anterior resection for rectal cancer. Intraoperative tumor visualization was possible in four out of five patients. Fluorescence signal could be detected 32 \pm 18 minutes after incision, while ink could be detected $42 \pm 21$ minutes after incision $(\mathrm{p}=0.53)$. No recurrence was diagnosed within three months after surgery. Ex vivo imaging identified a mean of $4.2 \pm 2.7$ fluorescent lymph nodes, which were appointed SLNs. One out of a total of 83 resected lymph nodes contained a micrometastasis. This node was not fluorescent. This technical note describes the feasibility of endoscopic tattooing of rectal cancer using ICG:nanocolloid and NIR fluorescence imaging during laparoscopic resection. Simultaneous SLN mapping was also feasible, but may be less reliable due to neoadjuvant therapy.
\end{abstract}

Key words: Fluorescence imaging, rectum, rectal cancer, feasibility study, surgery

\section{Introduction}

The introduction of total mesorectal excision (TME) combined with preoperative radiotherapy in patients with resectable rectal cancer has shown to reduce local recurrence rates from $11 \%$ to $5 \%$ compared to surgery alone (1). Tumor involvement at the resection margin remains the most important predictor for local recurrence (2). A careful description of the localization of the rectal tumor is therefore essential. In the era of laparoscopic surgery, this is even more challenging, especially when the tumor is small or located at the mesenteric intestinal border. Colonoscopy is the gold standard for detection of colorectal cancer. However, its ability to localize cancer has been called into question (3). Tumor localization can be wrongly assessed when the colonoscope is not completely straight. Endoscopic tattooing using ink to direct the surgeon has been performed since the 1960s (4). It results in reliable intraoperative localization, but not all tattoos are visible, especially when the tumor can be found below the peritoneal reflection or adjacent to the mesorectal envelope (5).

Recently, near-infrared (NIR) fluorescence imaging has been introduced for real-time intraoperative visualization of tumors, sentinel lymph nodes (SLNs)

Correspondence: A. L. Vahrmeijer, Department of Surgery, Albinusdreef 2, 2300 RC Leiden, The Netherlands, Fax: +31 71526 6750;

E-mail: a.l.vahrmeijer@lumc.nl 
Table 1. Patient characteristics.

\begin{tabular}{|c|c|c|c|c|c|c|c|c|c|}
\hline $\begin{array}{c}\text { Patient } \\
\text { no. }\end{array}$ & Gender & $\begin{array}{c}\text { Age } \\
\text { (years) }\end{array}$ & $\begin{array}{l}\text { Clinical TNM } \\
\text { Classification }\end{array}$ & $\begin{array}{l}\text { Distance to } \\
\text { dentate } \\
\text { line }(\mathrm{cm})\end{array}$ & $\begin{array}{c}\text { Neoadjuvant } \\
\text { therapy }\end{array}$ & $\begin{array}{c}\text { Localization of } \\
\text { tumor by NIR } \\
\text { fluorescence }\end{array}$ & $\begin{array}{c}\text { SLNs } \\
\text { detected by } \\
\text { NIR fluorescence }\end{array}$ & $\begin{array}{l}\text { LNs identified } \\
\text { at pathology }\end{array}$ & $\begin{array}{l}\text { Blue ink } \\
\text { visible }\end{array}$ \\
\hline 1 & M & 71 & cT2N0M0 & 15 & Radiotherapy & + & 5 & 12 & + \\
\hline 2 & M & 61 & cT3N2M0 & 7 & Chemoradiotherapy & + & 2 & 15 & + \\
\hline 3 & $\mathrm{~F}$ & 65 & cT3N1M0 & 18 & Radiotherapy & + & 3 & 12 & + \\
\hline 4 & $\mathrm{~F}$ & 70 & cT3N2M0 & 7 & Chemoradiotherapy & - & 5 & 18 & + \\
\hline \multirow[t]{2}{*}{5} & $\mathrm{~F}$ & 76 & cT2N0M0 & 9 & None & + & 4 & 26 & + \\
\hline & & $69 \pm 5.6$ & & $11.2 \pm 5.0$ & & $80 \%$ & $3.8 \pm 1.3$ & $16.6 \pm 5.8$ & $100 \%$ \\
\hline
\end{tabular}

and vital structures such as ureters (6). Advantages of NIR light (wavelength 700-900 nm) include high tissue penetration (several millimeters) and low tissue autofluorescence, providing high signal-to-background ratios. Indocyanine green (ICG) is currently the only clinically available $800 \mathrm{~nm}$ fluorophore and has been used with success in several clinical studies $(7,8)$. ICG could be a more suitable dye for tattooing, because of few side effects, relatively long absorption time and potentially increased detection using NIR fluorescence imaging compared to macroscopic color perception (9).

Besides endoscopic tattooing, injecting ICG may also assist in intraoperative detection of SLNs. Although surgery is often considered curative in node-negative rectal cancer, approximately $25 \%$ of these patients will develop disease recurrence (10). This is most likely caused by understaging of the resected lymph nodes (LNs). Micrometastases are easily missed by conventional histopathological examination, but examination of all $\mathrm{LNs}$ to detect micrometastases is time-consuming and expensive. Multilevel fine pathological examination of SLNs in colorectal cancer has been shown to improve tumor staging (11). Several studies report high detection and sensitivity rates by using ICG for the SLN procedure in different types of cancer, including gastrointestinal cancer (12-18). ICG is non-covalently absorbed by nanocolloid. The hydrodynamic diameter is thereby increased from $1 \mathrm{~nm}$ to approximately $50 \mathrm{~nm}(19,20)$. This improves accuracy, since molecules < approximately $10 \mathrm{~nm}$ quickly flow through the SLN to second tier LNs, whereas larger molecules require multiple hours to days to reach beyond the SLN. Using ICG-nanocolloid whether or not combined with Technetium-99m to identify SLNs has already successfully been described in patients (21-23). The aim of the present study was to assess the feasibility to localize tumors and SLNs using NIR fluorescence imaging after endoscopic tattooing with ICG:nanocolloid.

\section{Material and methods}

The study was approved by the Medical Ethics Committee of the Leiden University Medical Center and performed in accordance with the ethical standards of the Helsinki Declaration of 1975.

\section{Laparoscopic fluorescence imaging system}

Intraoperative NIR fluorescence imaging was performed using a laparoscopic high definition fluorescence imaging system (KARL STORZ GmbH \& Co. KG, Tuttlingen, Germany). The system included a plasma light guide and a $30^{\circ}, 10 \mathrm{~mm}$ laparoscope, applicable for white light (WL) and ICG imaging. Switching between WL and ICG mode was done by using a foot pedal.

\section{Preparation and injection of the probe}

ICG $(25$ mg vials, Pulsion Medical Systems, Munich, Germany) was dissolved in $5 \mathrm{ml}$ sterile water. Subsequently, $1 \mathrm{ml}$ of $5 \mathrm{mg} / \mathrm{ml} \mathrm{ICG}$ was diluted in $100 \mathrm{ml}$ sterile water $(50 \mu \mathrm{g} / \mathrm{ml}$ final concentration). Nanocolloid (0.5 mg vials, GE Healthcare, Eindhoven, the Netherlands) was dissolved in $3 \mathrm{ml}$ saline. $1.5 \mathrm{ml}$ $50 \mu \mathrm{g} / \mathrm{ml} \mathrm{ICG}$ was then mixed with $0.9 \mathrm{ml}$ of $0.167 \mathrm{mg} / \mathrm{ml}$ nanocolloid. After general anesthesia, prior to incision, $1.6 \mathrm{ml}$ ICG:nanocolloid containing $100 \mu \mathrm{g}$ nanocolloid and $50 \mu \mathrm{g}$ ICG was injected endoscopically at four peritumoral submucosal spots $(0.4 \mathrm{ml}$ per spot) by the gastroenterologist. A rectal tube was used to deflate the rectum after endoscopy.

\section{Surgical technique}

Included patients (Table I) underwent standard-ofcare laparoscopic low anterior resection performed by experienced surgeons. Peritumoral tattooing with India ink was performed by the gastroenterologist 

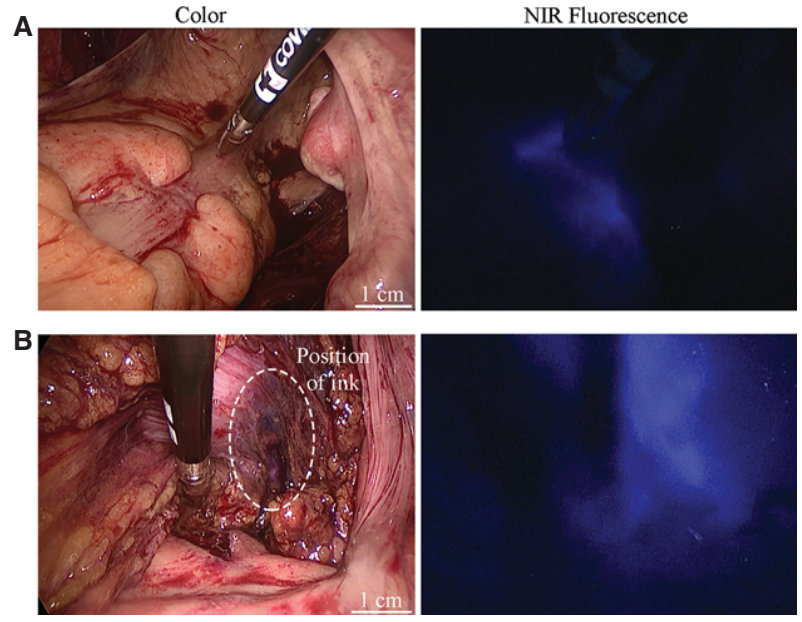

Figure 1. (A) Intraoperative laparoscopic NIR fluorescence imaging of the endoscopically injected probe ICG:nanocolloid in a patient with rectal cancer. India ink is not yet visible. (B) Intraoperative macroscopic visualization of India ink in the rectum. NIR fluorescence signal is also visible.

several weeks prior to surgery. In addition to the standard-of-care, NIR fluorescence imaging was performed at several time points during laparoscopic surgery to localize the tumor and SLNs.

\section{Ex vivo imaging}

After slicing of the specimen at least one day after surgery, fluorescence imaging was performed again at the Pathology Department with the previously described FLARE ${ }^{\mathrm{TM}}$ imaging system (24). Fluorescent LNs were appointed as SLNs and processed separately from non-fluorescent LNs. Standard pathologic assessment was performed by cytokeratin immunohistochemistry.

\section{Results}

The tumor could clearly be localized in four out of five patients (Figure 1A). One patient (patient no. 4) was injected with ICG:nanocolloid, but no intraoperative images were obtained due to an operator mistake that disabled the correct imaging settings. In all other patients the fluorescence signal was visible earlier than ink (Figure 1B). Fluorescence signals could be detected $32 \pm 18$ minutes after incision, while ink could be detected $42 \pm 21$ minutes after incision $(p=0.53)$. All resections were radical. No recurrence was diagnosed within three months after completion of the study. One patient (no. 2) developed anastomotic leakage, which was closed surgically. No other complications regarding the use of ICG:nanocolloid or fluorescence imaging occurred.

The mean time between injection and end of the procedure, i.e. the time for ICG:nanocolloid to migrate to the SLN, was $189 \pm 48$ minutes. During the procedure, a mean of $2.0 \pm 0.82$ fluorescent LNs could be visualized (Figure 2). Ex vivo imaging was performed in all five patients. Using the FLARE ${ }^{\mathrm{TM}}$ imaging system, a mean of $4.2 \pm 2.7$ fluorescent LNs per patient could be identified, which were appointed SLNs. The pathologist found $12.4 \pm 8.0$ additional LNs per patient by conventional method, which were appointed non-SLNs. One out of a total of 83 identified LNs contained a micrometastasis. However, this node (in patient no. 2) was not fluorescent.

\section{Discussion}

Advances in the treatment of rectal cancer have not only led to improved patient outcome, but also to challenges. Laparoscopic surgery results in significantly lower mortality and morbidity compared to open surgery (25), but it also deprives surgeons of tactile and visual feedback. Neoadjuvant radiochemotherapy decreases recurrence rates, but pathologic response makes identification of the primary tumor more difficult (5). Both laparoscopy and neoadjuvant therapy complicate the intraoperative localization of the tumor. These advances are especially an issue since incomplete resections are the single most
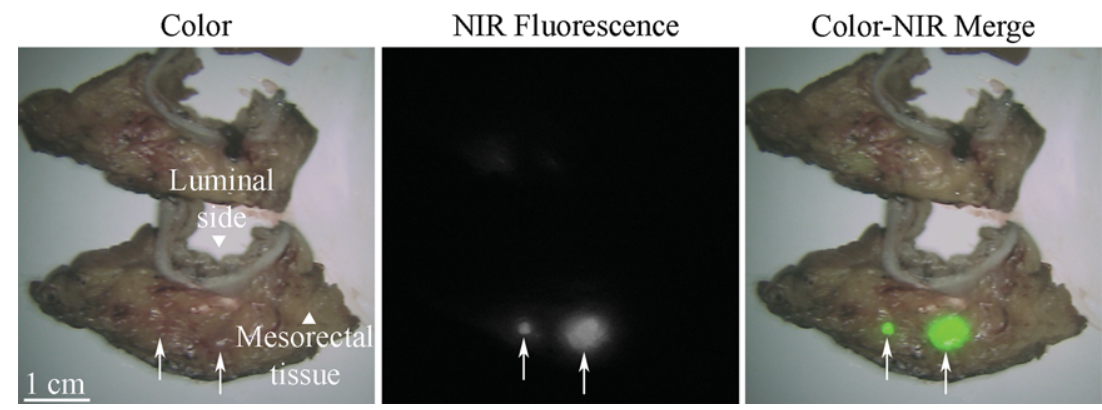

Figure 2. Ex vivo NIR fluorescence imaging of a resected and sliced rectum specimen using the FLARE ${ }^{\mathrm{TM}}$ camera system. Two fluorescent spots are visible (white arrows), which were appointed as SLNs. 
important factor for rectal cancer recurrence (2). Endoscopic tattooing using ink results in reliable intraoperative localization of colorectal cancer (26). However, not all tattoos are visible, because ink can be easily masked by overlying tissue.

The present study shows that endoscopic tattooing with ICG:nanocolloid is technically feasible. The NIR fluorescence signal was visible in all patients in whom imaging could be performed. In addition, the signal was not only seen earlier than ink, but was also better visible throughout the entire procedure. This is the result of a higher penetration depth of NIR light (several millimeters) compared to ink. Watanabe et al. (9) also used ICG for colonic tattooing. In all ten patients, the tumor border could be identified using NIR fluorescence imaging. The signal remained visible for at least 72120 hours after pre-operative endoscopic injection. However, we chose to perform endoscopic tattooing after general anesthesia to save our patients from the discomfort of yet another colonoscopy and another visit to the hospital. Although the tumor could be localized ten minutes earlier, the endoscopy during surgery neutralized this advantage. To be cost-effective, it should therefore be studied whether the ICG injection can be combined with the standard-of-care endoscopic tattooing with ink or can even replace it. This is, however, only possible if the retention time of ICG is sufficient.

In colorectal cancer patients, both blue dyes and radiotracers have been used as SLN tracers in in vivo and ex vivo settings, but both tracers have disadvantages (27). The use of gamma ray-emitting radiotracers requires involvement of a nuclear physician and localization requires a handheld gamma probe, which does not permit real-time visualization. Blue dyes cannot be seen through overlying tissue and can diffuse through the true SLN to $2^{\text {nd }}$ - and $3^{\text {rd }}$-tier nodes due to their small size. The use of ICG:nanocolloid may overcome these disadvantages and identify LNs which are candidates for multilevel fine pathological examination (11). Other studies describing the use of ICG and NIR fluorescence imaging in SLN identification in different types of cancer report detection rates of $90 \%$ to $100 \%$ and sensitivity rates of $82 \%$ to $100 \%(12-18)$. The detection rate is similar $(100 \%)$, but the only micrometastasis containing lymph node in the present study was not fluorescent (sensitivity: 0\%). Although the included number of patients is not enough to draw extensive conclusions, the difference may be explainable by the long course of neoadjuvant chemoradiotherapy this patient (patient no. 2) received, which has been shown to result in unreliable SLN procedures in rectal cancer (28). SLN mapping in rectal cancer using ICG:nanocolloid and NIR fluorescence imaging appears to perform just like other SLN mapping methods in rectal cancer, i.e. unreliably. However, it can still assist in identifying the necessary number of LNs required for pathologic TNM staging (29). In addition, in case no neoadjuvant therapy is given, e.g. in selected patients with stage cT1-cT2N0, this technique may have higher sensitivity. Arezzo et al. (25) showed the feasibility of SLN mapping using ICG and NIR fluorescence imaging during transanal endoscopic microsurgery (TEM) in three patients with $\mathrm{T} 0 / \mathrm{T} 1$ rectal cancer.

The currently used laparoscope was only capable of showing one light modus at a time. However, there are already camera systems available that can depict white light and NIR channels at the same time, and even produce white light-NIR overlay video for better anatomical orientation.

ICG is not a tumor-targeted probe. Hence, no tumor-specific signal can be expected. The accuracy of the fluorescence signal thus depends mainly on the accuracy of the gastroenterologist's injection. In the near future, tumor-specific probes, such as cRGDZW800-1 which targets integrins associated with neoangiogenesis, may be expected (30). Such probes have the potential to accurately localize tumor and its border in real-time during surgery. Furthermore, it makes endoscopic tattooing redundant, because these probes are injected intravenously prior to surgery.

\section{Conclusion}

This technical note describes the technical feasibility of endoscopic tattooing of rectal cancer using ICG: nanocolloid and NIR fluorescence imaging during laparoscopic resection. Simultaneous SLN mapping was also feasible, but may be less reliable.

\section{Acknowledgments}

We thank KARL STORZ GmbH \& Co. KG for supplying the laparoscopic near-infrared imaging system.

Declaration of interest: J.V. Frangioni is currently CEO of the Curadel Companies (Curadel, Curadel ResVet Imaging and Curadel Surgical Innovations). $\mathrm{He}$, his wife and children own equities in Curadel, which is commercializing FLARE technology. The authors report no conflicts of interest. The authors alone are responsible for the content and writing of the paper.

Disclaimer: John V. Frangioni, M.D., Ph.D.: FLARE $^{\text {TM }}$ technology is owned by Beth Israel Deaconess Medical Center, a teaching hospital of 
Harvard Medical School. Dr. Frangioni has started 3 for-profit companies, Curadel, Curadel ResVet Imaging, and Curadel Surgical Innovations, which has optioned FLARE ${ }^{\mathrm{TM}}$ technology for potential licensing from Beth Israel Deaconess Medical Center.

Source: This work was supported by the Dutch Cancer Society, grant no. UL2010-4732. This study was performed within the framework of the Center of Translational Molecular Medicine (project MUSIS, Grant 03O-202-04).

\section{References}

1. van Gijn W, Marijnen CA, Nagtegaal ID, Kranenbarg EM, Putter $\mathrm{H}$, Wiggers $\mathrm{T}$, et al. Preoperative radiotherapy combined with total mesorectal excision for resectable rectal cancer: 12-year follow-up of the multicentre, randomised controlled TME trial. Lancet Oncol. 2011;12:575-82.

2. Kellokumpu I, Vironen J, Kairaluoma M, Jantunen I, Kautiainen H, Nuorva K. Quality of surgical care, local recurrence, and survival in patients with low- and midrectal cancers following multimodal therapy. Int J Colorectal Dis. 2012;27:111-20.

3. Schoellhammer HF, Gregorian AC, Sarkisyan GG, Petrie BA. How important is rigid proctosigmoidoscopy in localizing rectal cancer? Am J Surg. 2008;196:904-8.

4. Knoernschild HE. The use of a tattooing instrument for marking colonic mucosa. Am J Surg. 1962;103:83-5.

5. Torres ML, McCafferty MH, Jorden J. The difficulty with localization of rectal cancer after neoadjuvant chemoradiation therapy. Am Surg. 2010;76:974-6.

6. Vahrmeijer AL, Hutteman $M$, van der Vorst JR, van de Velde CJ, Frangioni JV. Image-guided cancer surgery using near-infrared fluorescence. Nat Rev Clin Oncol. 2013; 10:507-18.

7. van der Vorst JR, Schaafsma BE, Hutteman M, Verbeek FP, Liefers GJ, Hartgrink HH, et al. Near-infrared fluorescenceguided resection of colorectal liver metastases. Cancer. 2013; 119:3411-18.

8. Schaafsma BE, Mieog JS, Hutteman M, van der Vorst JR, Kuppen PJ, Lowik CW, et al. The clinical use of indocyanine green as a near-infrared fluorescent contrast agent for image-guided oncologic surgery. J Surg Oncol. 2011;104: 323-32.

9. Watanabe $M$, Tsunoda A, Narita $K$, Kusano M, Miwa M. Colonic tattooing using fluorescence imaging with light-emitting diode-activated indocyanine green: a feasibility study. Surg Today. 2009;39:214-18.

10. de Campos-Lobato LF, Stocchi L, de Sousa JB, Buta M, Lavery IC, Fazio VW, et al. Less than 12 nodes in the surgical specimen after total mesorectal excision following neoadjuvant chemoradiation: it means more than you think!. Ann Surg Oncol. 2013;20:3398-406.

11. Vogelaar FJ, Reimers MS, van der Linden RL, van der Linden JC, Smit VT, Lips DJ, et al. The Diagnostic Value of One-Step Nucleic acid Amplification (OSNA) for Sentinel Lymph Nodes in Colon Cancer Patients. Ann Surg Oncol. 2014;21:3924-30.

12. Ankersmit $M$, van der Pas $M H$, van Dam DA, Meijerink WJ. Near infrared fluorescence lymphatic laparoscopy of the colon and mesocolon. Colorectal Dis. 2011;13: 70-3.
13. Cahill RA, Anderson M, Wang LM, Lindsey I, Cunningham C, Mortensen NJ. Near-infrared (NIR) laparoscopy for intraoperative lymphatic road-mapping and sentinel node identification during definitive surgical resection of early-stage colorectal neoplasia. Surg Endosc. 2012;26:197-204.

14. van der Vorst JR, Hutteman $M$, Gaarenstroom $\mathrm{KN}$, Peters AA, Mieog JS, Schaafsma BE, et al. Optimization of near-infrared fluorescent sentinel lymph node mapping in cervical cancer patients. Int J Gynecol Cancer. 2011;21: 1472-8.

15. Fujiwara M, Mizukami T, Suzuki A, Fukamizu H. Sentinel lymph node detection in skin cancer patients using real-time fluorescence navigation with indocyanine green: preliminary experience. J Plast Reconstr Aesthet Surg. 2009;62:e373-8.

16. Hirche C, Mohr Z, Kneif S, Doniga S, Murawa D, Strik M, et al. Ultrastaging of colon cancer by sentinel node biopsy using fluorescence navigation with indocyanine green. Int J Colorectal Dis. 2012;27:319-24.

17. Crane LM, Themelis G, Arts HJ, Buddingh KT, Brouwers $\mathrm{AH}$, Ntziachristos $\mathrm{V}$, et al. Intraoperative nearinfrared fluorescence imaging for sentinel lymph node detection in vulvar cancer: first clinical results. Gynecol Oncol. 2011;120:291-5.

18. Kusano M, Tajima Y, Yamazaki K, Kato M, Watanabe M, Miwa M. Sentinel node mapping guided by indocyanine green fluorescence imaging: a new method for sentinel node navigation surgery in gastrointestinal cancer. Dig Surg. 2008;25: $103-8$.

19. Ohnishi S, Lomnes SJ, Laurence RG, Gogbashian A, Mariani G, Frangioni JV. Organic alternatives to quantum dots for intraoperative near-infrared fluorescent sentinel lymph node mapping. Mol Imaging. 2005;4:172-81.

20. Buckle T, van Leeuwen AC, Chin PT, Janssen H, Muller SH, Jonkers $\mathrm{J}$, et al. A self-assembled multimodal complex for combined pre- and intraoperative imaging of the sentinel lymph node. Nanotechnology. 2010;21:355101.

21. Schaafsma BE, Verbeek FP, Rietbergen DD, van der Hiel B, van der Vorst JR, Liefers GJ, et al. Clinical trial of combined radio- and fluorescence-guided sentinel lymph node biopsy in breast cancer. Br J Surg. 2013;100:1037-44.

22. Matheron HM, van den Berg NS, Brouwer OR, Kleinjan GH, van Driel WJ, Trum JW, et al. Multimodal surgical guidance towards the sentinel node in vulvar cancer. Gynecol Oncol. 2013;131:720-5.

23. van der Poel HG, Buckle T, Brouwer OR, Valdes Olmos RA, van Leeuwen FW. Intraoperative laparoscopic fluorescence guidance to the sentinel lymph node in prostate cancer patients: clinical proof of concept of an integrated functional imaging approach using a multimodal tracer. Eur Urol. 2011; 60:826-33.

24. Troyan SL, Kianzad V, Gibbs-Strauss SL, Gioux S, Matsui A, Oketokoun R, et al. The FLARE intraoperative near-infrared fluorescence imaging system: a first-in-human clinical trial in breast cancer sentinel lymph node mapping. Ann Surg Oncol. 2009;16:2943-52.

25. Arezzo A, Passera R, Scozzari G, Verra M, Morino M. Laparoscopy for rectal cancer reduces shortterm mortality and morbidity: results of a systematic review and meta-analysis. Surg Endosc. 2013;27:1485-502.

26. Conaghan PJ, Maxwell-Armstrong CA, Garrioch MV, Hong L, Acheson AG. Leaving a mark: the frequency and accuracy of tattooing prior to laparoscopic colorectal surgery. Colorectal Dis. 2011;13:1184-7.

27. van der Pas MH, Meijer S, Hoekstra OS, Riphagen II, de Vet HC, Knol DL, et al. Sentinel-lymph-node procedure 
in colon and rectal cancer: a systematic review and metaanalysis. Lancet Oncol. 2011;12:540-50.

28. Braat AE, Oosterhuis JW, Moll FC, de Vries JE, Wiggers T. Sentinel node detection after preoperative short-course radiotherapy in rectal carcinoma is not reliable. Br J Surg. 2005;92:1533-8.

29. Kim YW, Kim NK, Min BS, Lee KY, Sohn SK, Cho CH. The influence of the number of retrieved lymph nodes on staging and survival in patients with stage II and III rectal cancer undergoing tumor-specific mesorectal excision. Ann Surg. 2009;249:965-72.

30. Verbeek FP, van der Vorst JR, Tummers QR, Boonstra MC, de Rooij KE, Lowik CW, et al. Near-Infrared Fluorescence Imaging of Both Colorectal Cancer and Ureters Using a LowDose Integrin Targeted Probe. Ann Surg Oncol. 2014;21: S528-37. 